\title{
THIRDSPACE, INTELLIGENT LEARNING ANALYTICS AND LANGUAGE LEARNING
}

\author{
Klaus Waschik, Konstantin Kharin \& Svetlana Kibardina
}
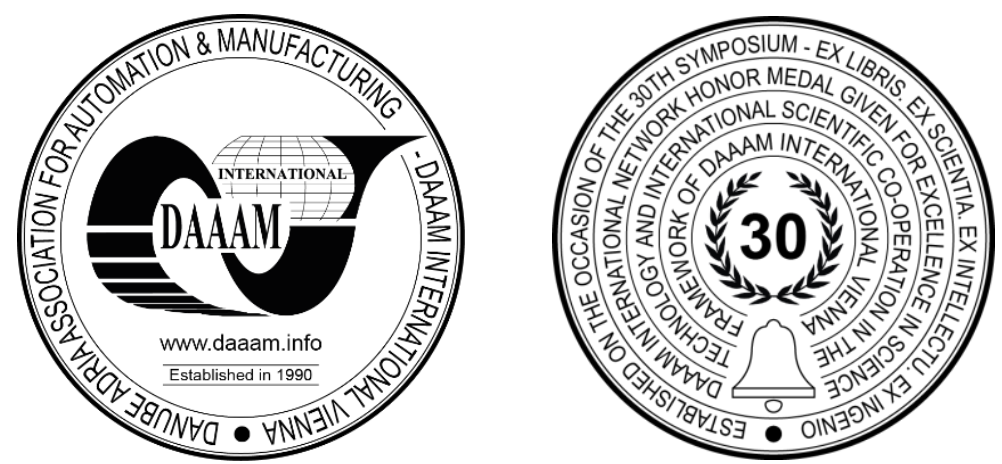

This Publication has to be referred as: Waschik, K[laus]; Kharin, K[onstantin] \& Kibardina, S[vetlana] (2019). Thirdspace, Intelligent Learning Analytics and Language Learning, Proceedings of the 30th DAAAM International Symposium, pp.0353-0358, B. Katalinic (Ed.), Published by DAAAM International, ISBN 978-3-902734-22-8, ISSN 1726-9679, Vienna, Austria

DOI: $10.2507 / 30$ th.daaam.proceedings.047

\begin{abstract}
The article focuses on the question of how social processes of individualisation also affect the acquisition of foreign languages and in what form the development of hybrid learning concepts and environments follow these tendencies. Hybrid learning environments refer to specific networks of classroom learning and online-based learning that have previously been understood as blended learning. However, the emergence of new, intelligent assisted learning systems makes it necessary to redefine hybrid-learning environments. The article therefore deals with the specific features and functions of intelligent tutoring in foreign language teaching and deals with the learning technology requirements that these systems must meet in order to be able to find a new qualitative place in hybrid learning environments. The learning environment LSI.online is used as an example to illustrate the central function of intelligent assistance.
\end{abstract}

Keywords: distant learning; hybrid learning; learning systems; personal learning environment; intelligent assistance.

\section{Introduction}

The latest trends have shown significant changes in recent years regarding the demand for language learning, learning expectations and time periods. Although the focus continues to be on classroom learning, there are clear shifts towards personalised learning, learning with new, widely available learning resources and technologies and a more conscious use of learning time available to learners for language acquisition. The background to this development is a change in basic attitudes towards foreign languages, their meaningfulness, status and application. Knowledge of foreign languages is increasingly seen as functional, as a necessary tool for communication in a limited context of use, less as a gain for personal expression or an enrichment of personality. The intrinsic value of a mastered foreign language is significantly less valuable than the functional value of its use.

For many learners, these processes of change tend not only to lead to a more porous individual language acquisition, but also to competition between classroom and online learning or learning with new, mobile learning technologies, which have been developed over the past 50 years with different names (CALL, CBT, WBT, LMS, PLE, etc.), programme structures and range of functions. In addition, learning via apps, training videos or more extensive commercial learning 
platforms on the internet has developed into a dynamic growth market, whereas the number of classroom-based learning opportunities is declining [1], [2].

The central question of the research and development project is directed at the problem of how intelligent tutoring systems in foreign language teaching must be redesigned in terms of content, function and didactics in order to make a qualitative contribution to an integral, analog-digital learning space in a changed environment of foreign language acquisition.

\section{Thirdspace and Hybrid Learning Arrangements}

The development of computer-based learning media in the 1970s and 1980s was marked by enthusiasm on the part of many researchers and programme developers with the hope that an ideal learning instrument would be available to compete directly with traditional classroom learning. Both advocates and critics directly compared these first, often simply structured PC programmes with classroom teaching, whereby - especially from the critics' point of view - the "obvious lack of a teaching person who organises learning activities was perceived as a shortcoming" [3].

In actual fact, the computer programmes of the first generation, mostly simple pattern drill exercises, were far from capable of guaranteeing a learning efficiency even close to that of classroom learning. Programmes of this kind offered few learning functions and usually covered only a very limited range of grammar and vocabulary.

In the following decades, despite numerous relevant studies, a higher degree of effectiveness could not be demonstrated exclusively by the medium of new learning technologies in comparison to traditional media [4]. Advantages of the new technologies, such as increased learning motivation and associated learning tools, were often compensated by the disadvantages in the form of the "isolation" of the learner and - as a result - a higher drop-out rate as well as relatively high costs for production and use of the media. In addition, in expectation of low sales figures or insufficient public acceptance - especially in the commercial sector - often only limited funds were used for the development of learning software, with the result that only simple programmes could be realised, which then seemed to confirm the modest expectations ex post.

The new media of the initial phase could therefore not seriously endanger the traditional teaching and learning model.

This situation only changed in the 2000s with the conceptual emancipation of autonomous, self-determined and therefore individualised learning: platforms such as Blackboard, Ilias or Moodle were introduced as comprehensive content management solutions or learning management systems at universities and further education institutions. However, these systems quickly proved to be primarily administrative and communication platforms for learning content, the subject-specific content of which often differed only slightly from traditional learning materials. In most cases, it was an add-on to classroom events or a material management system in the background. The extent to which this actually supported learning processes in the long term or only provided access to predefined learning options remains controversial $[5]$.

It was only with the introduction, development and implementation of so-called "hybrid learning arrangements" in the middle of the 2000s that functional and role-specific contradictions between technology-supported and classroombased learning (computers vs. teachers) could be partially overcome. Teachers and computers were now no longer competitors for the optimal teaching/learning, but rather - ideally - complementary components of an integral learning space. Significant advantages of hybrid learning arrangements in comparison to monolithic, one-dimensional learning proposal consist initially in the increased temporal and spatial flexibility of their use [4]. In addition, there is an increased variety of media and methodological variants that can be applied in a hybrid-learning scenario.

In terms of methodology and didactics, the question was raised as to how all components involved in the learning process can be networked in the sense of a comprehensive "zone of available assistance" of the "material, social and virtual learning space" in such a way that, on the one hand, the media- and learning-specific advantages of the respective components reinforce each other and, on the other hand, the "deficits" of one component can be compensated for by the strength of the other [6].

To give an example from foreign language teaching: the realistic simulation of a complex communication situation, which may require further intercultural competences, can be practised in a role play in classroom teaching with all the advantages of direct linguistic and action-related feedback by teachers much faster, more effectively, more dynamically and more sustainably than would be possible with the best VR or AR programmes, whose presentation of real activity scenarios may perhaps be more lifelike, but which neither provide the diversity and aleatoric potential of communication processes nor adequate professional feedback. On the other hand, learning programmes in this case have the advantage that they can prepare or follow up the corresponding communication situation lexically, grammatically or thematically in an individually adapted way, and thus provide a service that would be difficult to find in classroom teaching in terms of time and organisation.

Hybrid learning arrangements must therefore be measured from an efficiency perspective in terms of the extent to which they not only offer a simple addition to the individual performances of the components involved, but also in fact guarantee higher learning success in their specific combination. Efficiency here does not only mean the achievement of pedagogical goals, but also the use of resources related to learning success in the development or implementation of learning components. The didactic design of a hybrid learning arrangement represents on the one hand the conceptual order and at the same time the material base of all teaching/learning processes, on the other hand, it embodies the interface between material, social and virtual learning space. The didactic design of a hybrid learning arrangement thus represents 
the overall functional structure of learning options and practices, in which all spaces for learning are meaningfully and effectively related to one another and thus becomes the concrete content and functional filling of a Thirdspace of learning: "Thirdspace represents the interface between material and virtual space. It is neither the one nor the other, nor the addition, but rather the combination, the superimposition of these two spatial components" [5].

The hybridisation of teaching/learning in an essentially new learning space, called 'Thirdspace', presupposes in the best case a fundamentally new arrangement of the material and communicative components of learning, in which the different learning formats must be taken into account in terms of guided, assisted and autonomous learning. This new arrangement, which finds its manifestation in hybrid didactic design, implies not only an optimised interconnection of the learning elements according to their respective teaching/learning effects, but also a change of formats that makes sense from a learning psychology point of view and a continuous change of roles of the actors involved in the learning process [7]. For foreign language teaching, the different roles of the actors and the resulting teaching/learning behaviour can be described as follows:

\begin{tabular}{|l|c|c|c|}
\hline \multicolumn{1}{|c|}{ Teaching Method } & $\begin{array}{c}\text { Presenting Teaching } \\
\text { Method }\end{array}$ & $\begin{array}{c}\text { Developing Teaching } \\
\text { Method }\end{array}$ & $\begin{array}{c}\text { Exploratory Teaching } \\
\text { Behaviour }\end{array}$ \\
\hline The teaching procedure is ... & teacher-led, inductive & teacher-led, deductive & learner-led, inductive \\
\hline The role of teachers is ... & leading, purporting & developing, guiding & stimulating, advising \\
\hline The role of the learner is ... & $\begin{array}{c}\text { absorbing, } \\
\text { comprehending } \\
\text { processing } \\
\text { independently }\end{array}$ \\
\hline The learning contents ... & $\begin{array}{c}\text { participating, thinking } \\
\text { along, instructing } \\
\text { and the learners receive } \\
\text { them receptively }\end{array}$ & $\begin{array}{c}\text { and worked on by the } \\
\text { learners under guidance }\end{array}$ & $\begin{array}{c}\text { learners independently } \\
\text { are worked on by the }\end{array}$ \\
\hline
\end{tabular}

Table 1. Roles of the actors and the resulting teaching/learning behaviour [8]

The practice of blended learning, e.g. in the alternating or framework variant, takes into account the three teaching procedures differentiated according to teacher/learner role and activity profile. Virtual-based learning can be assigned both to a presenting teaching method (e.g. "inverted classroom") and to autonomous, independent learning.

However, alternating teaching-learning formats and their linkage with virtual or classroom learning do not yet say anything about the character and functioning of true hybrid learning, for which a content-related, functional and psychologically motivated networking of learning elements and practices (e.g. teaching-learning strategies) would be a prerequisite. A strict division into presence phases and virtual, autonomous learning segments would then not be sustainable in the long term, since virtual learning modules would also have a place in presence phases and virtually autonomous phases would be accompanied by tele-tutoring or coaching via Skype or other audio/video communications systems [9]. As stated in [3], "In hybrid learning arrangements, the presence elements must be realigned... Now that we no longer meet as a matter of course in event rooms, we are experiencing - perhaps much more strongly than before - the 'magic of presence'. The special aspect of the personal encounter can be experienced more clearly than before."

\section{Individualisation (Personalisation) of Learning}

Parallel to the development of new learning technologies, a paradigmatic change from a teacher-centred to a learnercentred concept of teaching has taken place over the last 20 years, in the centre of which - ideally - is an autonomous learning subject that organises its learning processes independently. The increase in a constructivist understanding of knowledge acquisition and learning had the consequence that the teacher tended to disappear as an entity controlling the learning process, primarily assuming coaching and assistance functions and accompanying the learner in his personal learning process. Although this was not directly linked to the provision of new learning technology instruments, it was accelerated by these.

It was precisely these technologies in the form of platforms, learning management systems and personal learning environments and the first adaptive tutor systems that provided the instruments to address the demand for greater individualisation and personalisation of learning. Individualisation, a sociological theory developed by Ulrich Beck in the 1980s, describes a completely different situation, namely a fundamental societal change through the release of the 
individual from fixed, e.g. family or religious relationships, but since the 2000s this has been transferred - quite inflationarily - to everyday cultural situations such as lifestyle, consumer and leisure behaviour and last but not least learning. At the same time, there was a clear revaluation of the term: individualisation of learning was now not only a desirable practice, but also an objective of how learning and teaching should be in the future. In this way, a conceptual triad was formed: Individualisation as a social guiding value was combined with the pedagogical idea of an autonomous learner with personal responsibility, for whom new learning technologies provided the appropriate instruments with which the learner could implement his own learning goals. The terms individualisation and personalisation were understood synonymously, but also with different emphasis.

In the case of individualisation, "emphasis was placed on the possibilities of tailoring learning (for example, on the question of how teaching can be tailored to the individual needs of the person), whereas personalisation is more about the aspect of self-management...". On the other hand, personalisation is also associated with the use of adaptive learning assistance systems, "where the computer as an 'intelligent' system takes on the role of advisor and tries to provide a service that is as tailor-made as possible" [10].

\section{Intelligent Learning Analytics and Foreign Language Learning}

Individualised learning is now also a demand of the time in foreign language teaching. There is nothing new about the realisation that it is the individual himself who learns and that the acquisition of knowledge and skills is therefore always based on a personal process of acquisition. What is new, however, is that this individual appears simultaneously in two roles, as a teacher who imparts something to himself as a learner or shows ways to develop it. This is where learning guidance usually begins, at the end of which there should be a self-responsible learning subject.

The fact that this is an ideal conception of a learner which is rarely achieved in reality, especially when the subject to be learned is a complex, foreign field of knowledge, such as Far Eastern foreign languages, raises the question of how and where individualised learning with self-determined learning and exercise courses can be supported and guided by data collected by support or tutorial systems during the learning process. This function is associated with the challenge of interpreting the collected data in relation to the learning individual (and possible comparison groups) on the one hand and in relation to the actual learning object on the other, in such a way that the learning recommendations provided by the tutorial or supporting system can actually offer professional help.

In the following, a distinction is made between assistance systems and tutorial systems. Although both offer help in the actual learning process, their subject area and also the type of support is different: assistance systems provide information on a specific issue (e.g. on the meaning of a word) through direct information in individual cases of need, tutorial systems, on the other hand, manage the learning process as a whole, usually on the basis of a more comprehensive evaluation of learning behaviour over longer periods of time.

At this point, a look at the current practice of tutorial systems is necessary: as a rule, these systems do not 'know' anything about the content they convey. In most cases, only general data on user behaviour is registered, such as the preference of visual material over verbal information, formal outcome of exercises (exercise results), the duration of learning, drop-out rates for learning elements or the specific selection (or deviation) of preconfigured learning paths. This data is typologised and correlated with the comparative data of other (analogue) learners and the final results obtained by these learners. As a result, a recommendation on learning behaviour or further learning pathways can be generated for the specific learner, which comes from the sample data of the other learners who have achieved the best learning success. Although tutorial systems of this type can be used in many different areas of learning, they require that each individual learning element have a closed, fully achieved learning objective. This situation, however, does not apply to the acquisition of a foreign language - for structural reasons - especially not if the learners have heterogeneous learning prerequisites, e.g. different levels of vocabulary, grammar (morphology, syntax, idiomatic language, etc.).

An assistance system based on general learning behaviour data is therefore not sufficient for the acquisition of foreign languages, since it is no longer a question of distinguishing between visual and verbal types of learners, for example, but of being able to respond to the learner's concrete deficits in knowledge and skills with a language-related, content-related response.

Basically, the question is raised as to what or how much an intelligent assistance system in foreign language acquisition needs to 'know' in structural terms about the language in order to be able to react adequately in the case of a specific knowledge deficit in addition to evaluating the general learning behaviour [11].

As an example, one can refer to the acquisition of reading proficiency, which is one of the central basic skills of foreign language acquisition. If a learner deals with a new, unknown text in a foreign language, a differentiated requirement profile develops relatively quickly that directly affects different language categories (word meanings, parts of speech, syntax, pronunciation, etc.). In order to understand the text, the learner needs not only information about the topic or background knowledge of the country, but also, and above all, help with the concrete linguistic phenomena appearing in the text. An assistance system must therefore be able to provide qualified information on the language phenomena requested by the learner (semantics, grammar, regional studies, etc.), which a traditional system based on general learning behaviour cannot of course provide.

The questions posed by the learner about the text continuously create a profile of individual knowledge deficits, which in turn becomes the object of intelligent interpretation by learning analytics. Since the assistance system can determine and document what kind of language the individual deficits of the learner are, e.g. whether the (missing) vocabulary, 
grammatical, stylistic or factographic areas of knowledge are most affected, the help function can also be specific in content. If, for example, a learner repeatedly uses certain grammatical tables or requests help with words that show this grammatical phenomenon, a deficit can be assumed in this area of grammar, to which an intelligent learning analytics can react accordingly with appropriate exercises or vocabulary training. In addition, intelligent learning analytics correlates individual learner requirement profiles with the comparative data of other learners who have worked on the same learning object. If this comparison involves identical patterns, corresponding help can also be provided for further work. This also makes it possible to forecast potential language difficulties on the basis of an analogy with the relevant deficit profiles of other learners, i.e. the tutorial system can alert a learner to possible questions or problems before working on a text.

Since each individual learner has different needs (in the sense of a concrete deficit profile), an assistance system, in the same way as a tutorial system based on it, must of course have its learning contents (e.g. texts in a course for acquiring reading competence) linguistically prepared, because only on such a basis can genuine, content-oriented and learning progress-related support be provided.

The individual use of the assistance system thus provides the evaluation data for a rule-based interpretation by the tutorial system, whereby the interpretation takes place according to a multi-stage procedure. Firstly, the learner-specific requirement profile is analysed without including other learner data and then compared with analogue learner data on a second level. The correlation of both levels can thus lead to a different recommendation for action, e.g. additional repetition exercises or information, than would be the case with an evaluation based solely on an analysis of individual learner data.

\section{Intelligent Learning Analytics in Thirdspace: a change of role}

With the development of intelligent tutorial systems based on a qualitative analysis of learner behaviour, the question of their significance and function in a hybrid learning arrangement is raised. The "zone of available assistance" defined by Luckin is changing massively through the use of intelligent systems, whereby the central advantage over traditional blended learning is precisely that the qualitative gap between classroom teaching and online learning is closed with regard to a comprehensive and equally specific support for all learning elements. In principle, a teacher in the classroom can react in detail to any request from the learner, apart from time and organisational limitations. An intelligent assistance and tutoring system also offers this service, whereby such a system is ubiquitously and continuously available. This kind of adaptation of functions allows a change in the prioritisation of the teaching environment.

While classroom teaching has traditionally been the dominant way of teaching foreign languages and the online environment has been subordinate or secondary to it in terms of content and function, the use of an intelligent analysis and assistance tool allows a change of role. The digital learning environment becomes the basis of a learning continuum in which the presence phases are included. This also changes the role and content of the classroom part. Traditionally, this included all language skills that the online area had to repeat, expand and consolidate. The classroom part can now specialise in those skills where oral communication (speaking and listening skills) is the dominant area. The division of functions thus offers a real gain in efficiency in terms of learning outcome and time. A prerequisite for equivalence produced in this way is that the assistance provided in the virtual learning area must not fall behind that provided in the classroom.

\section{Intelligent Assistance and Tutoring using LSI.online as an Example}

The requirements for an intelligent assistance and tutoring system described above can be illustrated using the learning platform (LMS) LSI.online of the Landesspracheninstitut (LSI) in the Ruhr University Bochum as an example [12]. Since 2010, LSI.online has been developed for the teaching of Russian and German as a foreign language. From 2013 onwards, LSI has been expanded for Arabic, Chinese, Japanese and Korean. As a learning platform, it accompanies LSI's classroom courses and offers language courses in an exclusive online mode (without attendance modules). LSI.online has an Author, User and Course Management System with which the learning content is created or conveyed and the learners are monitored. In addition, LSI.online has a system for evaluating learner data and an intelligent tutorial system. Furthermore, communication functions (asynchronous chat with teachers, learner forum) are implemented in LSI.online.

Although LSI.online also has numerous functions for the multimedia design of learning content (video, audio, images, animations, etc.), with which listening comprehension, situational, video-based speech training and writing skills can be practiced, the core functions of the platform lie in the development of reading competence, grammar and vocabulary. It is precisely here that the advantages of learning with digital instruments can be seen, since the acquisition of reading competence does not necessarily require the presence of a teacher, since the relevant assistance functions can also be guaranteed by the platform itself.

Regarding the assistance system: The LSI.online assistance system is implemented in the user version. It has the following characteristics: each text that forms the basis of the acquisition of reading competence has five text view modes (normal mode without further help, audio mode, grammar mode, dictionary mode, introductory vocabulary mode). Each word form appearing in the text is associated with the corresponding contextual translation, as well as with its grammatical (morphological, syntactic) categories, which in turn refer to an extensive reference grammar in table form.

By clicking on a word, the learner signals that he needs help with its semantic, morphological or syntactic background. For Chinese, there are other aids available, e.g. for combinations of characters. 
The tutorial system: With the corresponding clicks, the learner not only forms his individual word list, which is processed parallelly with a vocabulary trainer, but he also creates his own personal linguistic requirement profile, e.g. by clicking on words with certain grammar phenomena and attached tables. The significant accumulation of specific enquiries thus gives an indication of particular linguistic deficits of the learner, to which the tutorial system can make precise supplementary or repetitive offers (exercises, vocabulary work).

Further information on learning progress is provided by the exercises assigned to the texts, which are based didactically on a quaternary response methodology. The number of exercises completed, their degree of repetition and the exercise result achieved provide data on work behaviour and individual problem areas that are also included in the learning analysis.

In addition, the evaluation system, in the form of a comprehensive report that presents its results transparently to both the learner and the teacher, analyses the learning behaviour of other learners who have worked with the same course or text and incorporates this correlation data into the concrete assistance of the tutorial system.

LSI.online therefore has a primary assistance system that provides the assistance needed directly in the learning process by means of corresponding language data. The content structure of these support tools (for requested language phenomena) provides the basis for a secondary evaluation of the learning behaviour (deficit monitoring), from which rule-based recommendations are generated, which not only cover the general learning behaviour, but above all also the language content side of the learning process.

\section{Future perspectives}

The focus of the further development of LSI.online, but also of relevant complementary research, is on the one hand the definition, development and implementation of rule-based learning models, which form the basis for concrete, situation-related assistance. On the other hand, the developments focus on interpretation approaches, such as how linguistic material to be learned can be prepared in such a way that it optimally compensates for individual learning and knowledge deficits. In this context, the question of flexible, learner-indexed learning paths, learning design and learning alternatives is of particular importance. Intelligent tutoring systems should therefore be developed with a view to content structures and concrete learning requirements.

\section{References}

[1] A strong year for the "little ones". Results of the mmb industry monitor "E-Learning Economy". Essen 2018.

[2] Konecki, M. (2014). Problems in Programming Education and Means of Their Improvement, Chapter 37 in DAAAM International Scientific Book 2014, pp.459-470, B. Katalinic (Ed.), Published by DAAAM International, ISBN 978-3-901509-98-8, ISSN 1726-9687, Vienna, Austria

[3] Kerres, M. (2002). Combining online and presence elements in hybrid learning arrangements. // A.Hohenstein, K. Wilbers (ed.) Manual E-Learning. Cologne 2002. cit. to: https://learninglab.uni-due.de/sites/default/files/kombihybridenLA_0.pdf. (07.10.2019) S.1

[4] Kerres, M. \& Jechle, T. (1999). Hybrid Learning Arrangements: Personal Services in Multi- and Telemedial Learning Environments. // Yearbook Work, Education, Culture. Vol. 17 Recklinghausen 1999, p. 22

[5] Edinger, E.-Ch. \& Reimer, R.T.D. (2015). Thirdspace as a hybrid-learning environment. The combination of material and virtual learning spaces. Quote from: http://www.digitallernen.ch/wp-content/uploads/2015/10/EdingerReimer-2015-Thirdspace-als-hybride-Lernumgebung.pdf . S. 205

[6] Luckin, R. (2016). EOR Model and Design Framework. Quote from: http://bit.ly/1LQ6A3Z

[7] Schön, S., Ebner, M. \& Schön, M. (2016). Fusion of digital and analog teaching and learning formats. University Forum on Digitisation No. 25 (2016) P. $15 \mathrm{ff}$.

[8] Richter, C. (2008). Teaching formats for media knowledge transfer, Erfurt 2008.

[9] Kuvshinov, S. \& Kharin, K. (2018). Data Visualization on Distributed Display Facilities in a Professional Distance Learning System, Proceedings of the 29th DAAAM International Symposium, pp. 0411-0415, B. Katalinic (Ed.), Published by DAAAM International, ISBN 978-3-902734-20-4, ISSN 1726-9679, Vienna, Austria

[10] Deimann, M. (2016). Stronger Individualisation of Teaching through New Media, University Forum on Digitisation, Working Paper No. 26 2016. p. 10

[11] Sottilare, R., Graesser, A., Hu, X. \& Holden H., (Hgg.) (2013). Design Recommendations for Intelligent Tutoring Systems, Orlando 2013, p. 67 ff.

[12] Waschik, K. \& Kibardina, S. (2018). Foreign languages 4.0: Methodological and technological challenges in the context of personalisation and artificial intelligence // Theory and methodology of foreign language teaching: traditions and innovations. Shatilov readings. St. Petersburg 2018, p. 19-23. 